\title{
Anticancer Efficacy and Mechanism of Amentoflavone for Sensitizing Oral Squamous Cell Carcinoma to Cisplatin
}

\author{
CHENG-HSIEN CHEN ${ }^{*}$, YI-CHI HUANG ${ }^{2 *}$, YUAN-HAO LEE $^{3 *}$, ZHAO-LIN TAN $^{4}$, CHIA-JUNG TSAI ${ }^{5}$, \\ YAO-CHEN CHUANG ${ }^{6,7}$, HSI-FENG TU ${ }^{8,9 \dagger}$, TA-CHIH LIU ${ }^{10 \dagger}$ and FEI-TING $\mathrm{HSU}^{4 \dagger}$ \\ ${ }^{1}$ Surgical Department of Show Chwan Memorial Hospital, Changhua, Taiwan, R.O.C.; \\ ${ }^{2}$ Department of Radiology, Asia University Hospital, Taichung, Taiwan, R.O.C.; \\ ${ }^{3}$ Department of Radiation Physics, Division of Radiation Oncology, \\ The University of Texas MD Anderson Cancer Center, Houston, TX, U.S.A.; \\ ${ }^{4}$ Department of Biological Science and Technology, China Medical University, Taichung, Taiwan, R.O.C.; \\ ${ }^{5}$ Department of Medical Imaging and Radiological Sciences, I-Shou University, Kaohsiung, Taiwan, R.O.C.; \\ ${ }^{6}$ Faculty of Chinese Medicine, Macau University of Science and Technology, Macau SAR, P.R. China; \\ ${ }^{7}$ Kiang Wu Nursing College of Macau, Macau SAR, P.R. China; \\ ${ }^{8}$ Department of Dentistry, National Yang-Ming University Hospital, Yilan, Taiwan, R.O.C.; \\ ${ }^{9}$ Department of Dentistry, Dental School, National Yang-Ming University, Taipei, Taiwan, R.O.C.; \\ ${ }^{10}$ Division of Hematology-Oncology, Department of Internal Medicine, \\ Chang Bing Show Chwan Memorial Hospital, Changhua, Taiwan, R.O.C.
}

\begin{abstract}
Background/Aim: Nuclear factor kappa B (NF-kB) inactivation and apoptosis activation have been shown to enhance the anticancer effect of cisplatin in oral squamous cell carcinoma (OSCC). Amentoflavone may suppress $N F-k B$ activity and trigger apoptosis in different types of cancer. The aim of this study was to investigate the anticancer effect and mechanism of amentoflavone in combination with cisplatin in OSCC. Materials and Methods: We investigated the combination effect and mechanism of amentoflavone and cisplatin via cell viability analysis, flow cytometry-based apoptosis analyses, transwell migration/invasion assay, immunofluorescence staining and western blotting assay. Results: Both amentoflavone and QNZ
\end{abstract}

This article is freely accessible online.

\begin{abstract}
${ }^{*}+$ These Authors contributed equally to this study.
Correspondence to: Hsi-Feng Tu, Department of Dentistry, National Yang-Ming University Hospital, Yilan, Taiwan, R.O.C. Tel: +886 937546801, email: hsifeng@gmail.com; Ta-Chih Liu, Division of Hematology-Oncology, Department of Internal Medicine, Chang Bing Show Chwan Memorial Hospital, Changhua, Taiwan, R.O.C. Tel: +886965107388, e-mail: dx066@ cbshow.org.tw; Fei-Ting Hsu, Department of Biological Science and Technology, China Medical University, Taichung, Taiwan, R.O.C. Tel: +886 422053366, ext. 2532, Fax: +886 422053764, e-mail: sakiro920@mail.cmu.edu.tw
\end{abstract}

Key Words: Amentoflavone, cisplatin, oral squamous cell carcinoma, NF-kB, apoptosis.
(NF-kB inhibitor) significantly increased cisplatin-induced cytotoxicity. Amentoflavone reduced cisplatin-triggered $N F-k B$ activity and enhanced cisplatin-induced intrinsic caspasedependent and independent apoptotic pathways. Moreover, amentoflavone augments cisplatin-suppressed invasion and migration ability of OSCC cells. Conclusion: Inactivation of NF${ } B$ and induction of apoptosis through intrinsic caspasedependent and independent apoptotic pathways are associated with amentoflavone enhanced anti-OSCC efficacy of cisplatin.

Oral squamous cell carcinoma (OSCC) is the most common form of head and neck cancers, which occur in the oral cavity and oropharynx (1). Long-term exposure to carcinogens such as tobaccos, betel nuts and alcohol, is conducive to OSCC formation (2). Cisplatin, which inhibits tumor cell growth by inducing DNA damage, is used to treat patients with OSCC $(3,4)$. Over $30 \%$ of OSCC patients are insensitive to cisplatin treatment. Therefore, development of cisplatin sensitizers may offer therapeutic benefits for OSCC patients treated with cisplatin $(5,6)$.

Clinical and preclinical studies revealed that combination of cisplatin with other drugs or treatment modalities resulted in better therapeutic outcomes than cisplatin alone or a single modality treatment in OSCC. The combination of postoperative radiotherapy and cisplatin was shown to significantly improve recurrence-free and overall survival compared to radiotherapy alone in OSCC patients (7). For instance, vitamin D and suberoylanilide hydroxamic acid (SAHA, a histone deacetylase inhibitor), have been found to sensitize OSCC to cisplatin 
through suppression of nuclear factor kappa B (NF-kB) activation (5), as well as to enhance cisplatin-inhibited tumor growth of OSCC by induction of apoptosis (8).

It is anticipated that the combination of $N F-k B$ inactivation and the induction of apoptosis enhance the antiOSCC efficacy of cisplatin. Amentoflavone (AF), a multifunctional compound isolated from herbal plants, has been presented to inhibit tumor cell growth and invasion through reducing NF- $\mathrm{KB}$ signaling and inducing apoptosis in breast cancer, hepatocellular carcinoma, and glioblastoma (912). In addition, amentoflavone can enhance sorafenibinduced cytotoxicity through triggering the extrinsic and intrinsic apoptotic pathways of HCC (13). Nevertheless, the ability of amentoflavone to sensitize OSCC to cisplatin is ambiguous. The major purpose of the present study was to investigate the efficacy and mechanism of action of amentoflavone to sensitize OSCC to cisplatin in vitro.

\section{Materials and Methods}

Reagents and antibodies. Amentoflavone (AF), cisplatin (CIS), dimethyl sulfoxide (DMSO), Triton $X$ and MTT (3-(4,5Dimethylthiazol-2-yl-2,5- Diphenyltetrazolium Bromide)) were all purchased from Sigma Aldrich Corp. (St. Louis, MO, USA). Matrigel were purchased from Corning (Tewksbury, MA, USA). BAX, BAK, NF-kB p65 (ser536), NF-kB p65, $\beta$-actin, EndoG, AIF were all purchased from (Elabscience, Houston, TX, USA). NF-kB inhibitor (QNZ) 4-N-[2-(4-phenoxyphenyl)ethyl]quinazoline-4,6-diamine (QNZ) was obtained from Selleckchem (Houston, TX, USA).

Cell culture. SAS cells were acquired from Dr. Kai-Wen Hsu's Lab (China Medical University) and seeded in Dulbecco's Modified Eagle's (DMEM) medium containing 10\% FBS and 1\% PenicillinStreptomycin (Penicillin G Sodium Salt: 10,000 units $/ \mathrm{ml}$; Streptomycin Sulfate: $10 \mathrm{mg} / \mathrm{ml}$ ). SAS cells were incubated in a $37^{\circ} \mathrm{C}$ incubator under a humidified $5 \% \mathrm{CO}_{2}$ atmosphere. Cell culture related products were all obtained from Thermo Fisher Scientific Inc., MA, USA.

Cell morphology, cell viability and combination index analyses. SAS cells were seeded as $3 \times 10^{4}$ cells/well in 96-well plate and incubated overnight. Cells were treated with amentoflavone $(0,100,150,200$, $300 \mu \mathrm{M})$, QNZ $(0.5 \mu \mathrm{M})$ and cisplatin $(0-5 \mu \mathrm{g} / \mathrm{ml})$ for $24 \mathrm{~h}$. Cell morphology was analyzed with a Nikon ECLIPSE Ti-U microscope (Minato City, Tokyo, Japan). MTT assay was used for cell viability analysis. After treatment of cells with the MTT reagent (stock 5 $\mathrm{mg} / \mathrm{ml}$, diluted ten times with medium), cells were incubated in a $37^{\circ} \mathrm{C}$ incubator for $4 \mathrm{~h}$. Living cells were detected by a SpectraMax iD3 microplate reader (Molecular Devices, San Jose, CA, USA), as previously described (14). The combination index (CI) analysis was used to identify suitable combination dosage. The CI value calculation was performed by the CompuSyn software (ComboSyn, Paramus, NJ, USA), which was developed by Chou and Talalay (15).

Mitochondria membrane potential $\left(\Delta \Psi_{m}\right)$ analysis. SAS cells were seeded as $5 \times 10^{5}$ cells/well in a 6-well plate for overnight incubation. Cells were treated with $100 \mu \mathrm{M}$ amentoflavone and 1 $\mu \mathrm{g} / \mathrm{ml}$ cisplatin for $48 \mathrm{~h}$. After treatment, cells were harvested and stained with $4 \mu \mathrm{M} 3,3^{\prime}$-dihexyloxacarbocyanine iodide ( DiOC $_{6}$ ) dye for $30 \mathrm{~min}$ in the dark (Thermo Fisher Scientific). After staining, fluorescence intensity from cells were evaluated by NovoCyte flow cytometry. The results of the staining were measured using NovoExpress ${ }^{\circledR}$ software (Agilent Technologies Inc., Santa Clara, CA, USA).

Cell cycle subG1 phase and annexin-V/PI analyses. SAS cells were seeded as $5 \times 10^{5}$ cells/well in 6-well plate for overnight incubation. Cells were treated with $100 \mu \mathrm{M}$ amentoflavone and $1 \mu \mathrm{g} / \mathrm{ml}$ cisplatin for $48 \mathrm{~h}$. For cell cycle subG1 analysis, cells were harvested and fixed with $75 \%$ ethanol overnight at $-20^{\circ} \mathrm{C}$. The next day, cells were stained with PI solution (for cell cycle analysis, 40 $\mu \mathrm{g} / \mathrm{ml}$ PI, $100 \mu \mathrm{g} / \mathrm{ml}$ RNase and $1 \%$ Triton X-100 in PBS) for 30 min at $37^{\circ} \mathrm{C}$. For annexin-V/PI analysis, cells were harvested and stained with Annexin-V/FTC apoptosis detection kit (Vazyme Biotech Co. Lt, Nanjing City, PR China) in the dark for $30 \mathrm{~min}$ at $37^{\circ} \mathrm{C}$. After different staining procedures, apoptosis-related signals in cells were finally evaluated by NovoCyte flow cytometry and quantified by NovoExpress ${ }^{\circledR}$ software (16).

Caspase-3, caspase- 8 and caspase- 9 analyses. SAS cells were seeded at a density of $5 \times 10^{5}$ cells/well in 6-well plates for overnight incubation. Cells were treated with $100 \mu \mathrm{M}$ amentoflavone and 1 $\mu \mathrm{g} / \mathrm{ml}$ cisplatin for $48 \mathrm{~h}$. CaspGLOW ${ }^{\mathrm{TM}}$ Fluorescein Cleaved Caspase-3, CaspGLOW ${ }^{\mathrm{TM}}$ Fluorescein Cleaved Caspase-8, and CaspGLOW $^{\text {тм }}$ Fluorescein Cleaved Caspase-9 staining kit were purchased from Biovision (Mountain View, CA, USA). For activation of caspase- 3 , caspase- 8 and caspase- 9 , the staining procedure was performed according to the manufacturer's protocol and as previously described $(17,18)$.

Invasion and migration transwell assay. SAS cells were seeded at a density of $3 \times 10^{6}$ cells/well in $10 \mathrm{~cm}$ dishes for overnight incubation. Invasion and migration analyses were performed by the Corning $8 \mu \mathrm{m}$ transwell system (with or without matrigel) as previously described (18). Membranes from transwells were stained, photographed using the Nikon ECLIPSE Ti-U microscope and quantified by ImageJ software (version 1.50, National Institutes of Health, Bethesda, MD, USA) (18).

Western blot. SAS cells were seeded at a density of $3 \times 10^{6}$ cells/well in $10 \mathrm{~cm}$ dishes for overnight incubation. Cells were treated with $100 \mu \mathrm{M}$ amentoflavone and $1 \mu \mathrm{g} / \mathrm{ml}$ cisplatin for $48 \mathrm{~h}$. Total protein was harvested, separated by $8-12 \%$ SDS pages, and transferred onto polyvinylidene difluoride (PVDF) membranes. Membranes were then incubated with primary antibodies, including BAX, BAK, NFкB p65 (Ser536), NF-кB p65 and $\beta$-actin (Cell Signaling Technology, Danvers, MA, USA). Detailed procedure is described in a previous study (19).

Immunofluorescence (IF) staining assay. SAS cells were seeded at a density of $2.5 \times 10^{4}$ cells/well in a 4 -well chamber slice overnight (Nunc $^{\mathrm{TM}}$ Lab-Tek $^{\mathrm{TM}}$ II Chamber slide ${ }^{\mathrm{TM}}$, Thermo Fisher Scientific, Fremont, CA, USA). Cells were treated with $100 \mu \mathrm{M}$ amentoflavone and $1 \mu \mathrm{g} / \mathrm{ml}$ cisplatin for $48 \mathrm{~h}$. After treatment, cells were fixed with $4 \%$ paraformaldehyde for $15 \mathrm{~min}$, permineralized with $0.1 \%$ TrtitonX-100, washed 3 times with PBST (phosphate-buffered saline, $0.1 \%$ Tween-20), and blocked with blocking buffer (1\% BSA) for $1 \mathrm{~h}$ at $25^{\circ} \mathrm{C}$. Cells were then incubated with a primary antibody in 
A

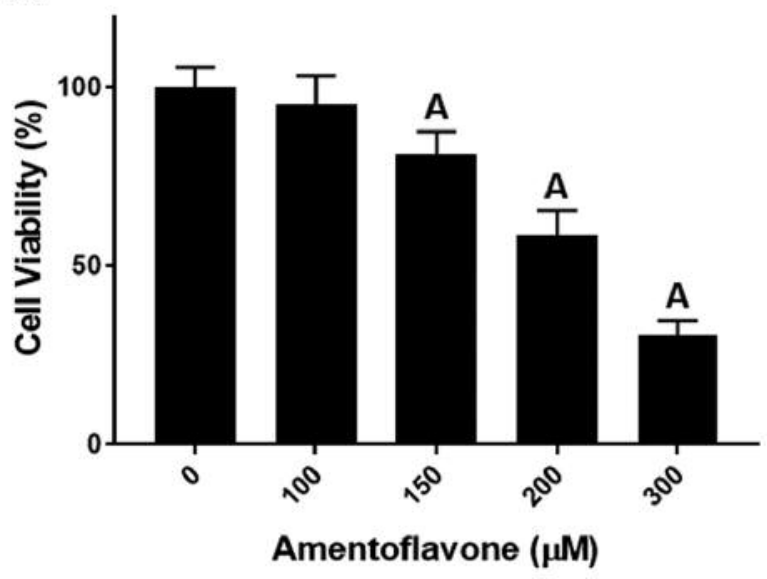

C

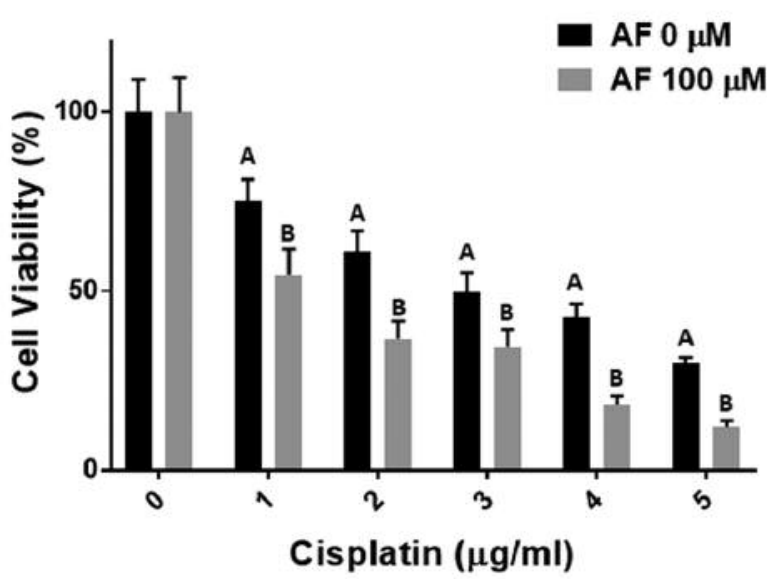

E
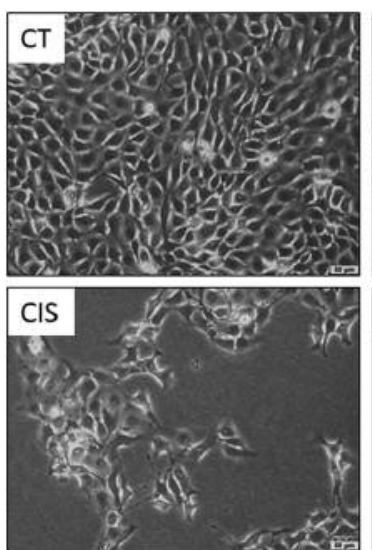
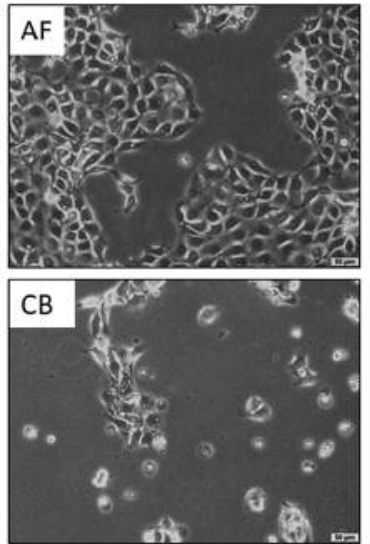

B

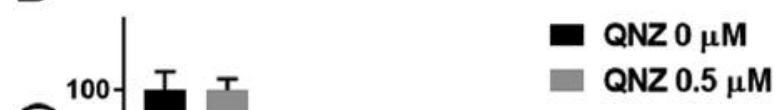

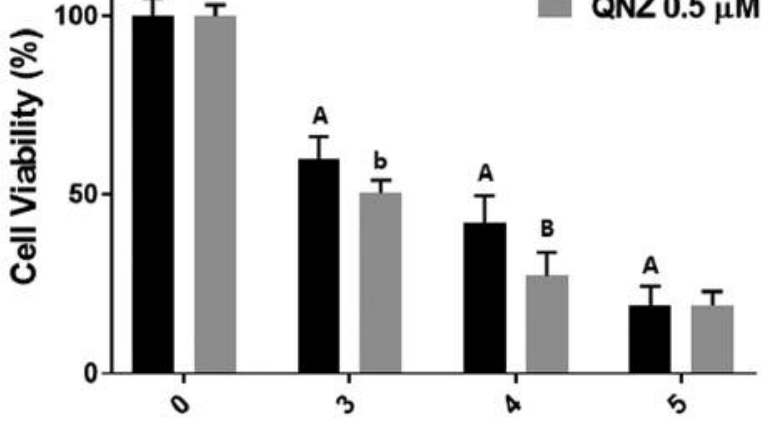

Cisplatin $(\mu \mathrm{g} / \mathrm{ml})$

D

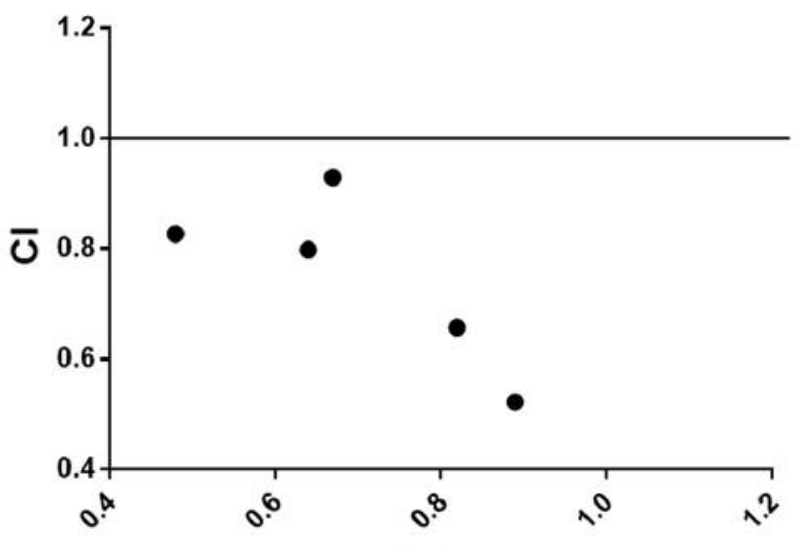

Effect

F

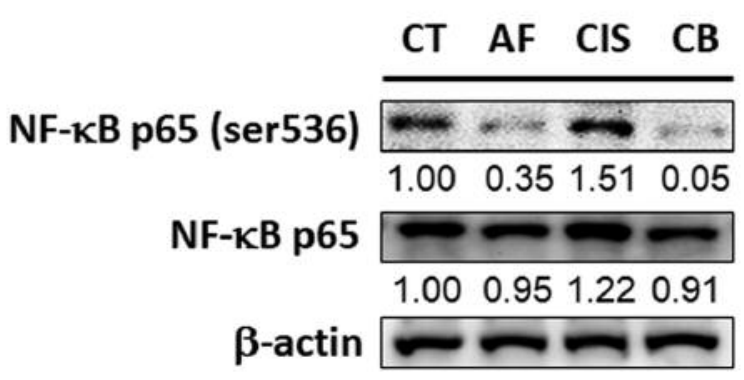

Figure 1. Cytotoxicity effect of amentoflavone and cisplatin in SAS cells. MTT assay results of (A) amentoflavone alone, (B) cisplatin combined w/o $0.5 \mu \mathrm{M}$ QNZ and (C) cisplatin combined w/o $100 \mu \mathrm{M}$ amentoflavone treatment for $24 \mathrm{~h}$ in SAS cells. (D) The CI value of the combination treatment. (E) The morphology and density change of SAS cells after amentoflavone, cisplatin and combined treatment. $(F)$ The protein expression of $N F-k B$ after treatment as analysed by Western blotting. Scale bar $=50 \mu \mathrm{m} .{ }^{A}$ p-value $<0.01 \mathrm{vs}$. non-treated group; ${ }^{b}$-value $<0.05,{ }^{B} p$-value $<0.01 \mathrm{vs}$. single treatment group; AF: amentoflavone; CIS: cisplatin; CB: combination. 
blocking buffer (1:300) overnight at $4^{\circ} \mathrm{C}$. After 3 washes, cells were stained with Alexa Fluor 488 conjugated secondary antibody (1:400) in blocking buffer for $1 \mathrm{~h}$ in the dark. Finally, chamber slices were covered by cover slips $(24 \times 50 \mathrm{~mm})$ and DAPI mounting medium. IF staining slides were photographed by Zeiss Axio Scope.A1 fluorescence microscope.

Statistical analysis. Significant difference between groups was analyzed by one-way ANOVA using Microsoft excel 2017 version. $p$-Values less than 0.05 were considered as statistically significant. Data are presented as mean \pm standard deviation.

\section{Results}

The promotion of cisplatin-induced cytotoxicity by amentoflavone was associated with $N F-k B$ inhibition in OSCC cells. As showed in Figure 1A, SAS cells viability was decreased by amentoflavone in a dose-dependent manner. Then, we identified whether the inhibition of NF-kB by QNZ induces the cytotoxicity of cisplatin. As illustrated in Figure 1B, viability was markedly reduced after treatment with QNZ combined with cisplatin as compared to cisplatin treatment alone. Therefore, we aimed to identify whether amentoflavone acts through NF$\mathrm{kB}$ to enhance the toxicity of cisplatin in OSCC. The combination of amentoflavone with cisplatin displayed superior cytotoxicity (Figure 1C). Then, we calculated the suitable combination dosage to obtain a synergistic effect with amentoflavone and cisplatin. As indicated by the CI value (CI=0.82), $100 \mu \mathrm{M}$ of amentoflavone combined with $1 \mu \mathrm{g} / \mathrm{ml}$ of cisplatin may synergistically decrease cells viability (Figure 1D and Table I). Bright field images of SAS cells obtained with a microscope, displayed a decreased density and cells shrinkage after the combined treatment (Figure 1E). Furthermore, the phosphorylation of NF-kB induced by cisplatin was diminished by amentoflavone (Figure 1F). In summary, we suggested that the cytotoxicity of cisplatin can be enhanced by amentoflavone via $\mathrm{NF}-\mathrm{kB}$ inactivation.

Amentoflavone enhances cisplatin-induced apoptosis in OSCC cells. To identify the apoptosis effect of amentoflavone combined with cisplatin, we investigated the expression levels of several apoptosis-related markers. As shown in Figure 2A and B, cleaved caspase-3 was activated by the combination of amentoflavone with cisplatin. The percentage of cells in the subG1 phase increased after treatment with cisplatin and was further increased after treatment with amentoflavone combined with cisplatin (Figure 2C and D). Furthermore, the percentage of cells in the $G_{1}$ phase increased after treatment with cisplatin alone or the combination (Figure 2E).

Amentoflavone enhances cisplatin-induced intrinsic caspasedependent and independent apoptosis in OSCC cells. After confirming the apoptosis effect of amentoflavone combined
Table I. Combination index value of amentoflavone combined with cisplatin. The CI value calculation was performed by CompuSyn software (ComboSyn, Paramus, NJ, USA). The combination effect was defined as follow, synergism $(\mathrm{CI}<1)$, additive Effect $(\mathrm{CI}=1)$ and antagonism $(\mathrm{CI}>1)$.

\begin{tabular}{lcccc}
\hline $\begin{array}{l}\text { Dose of } \\
\text { amentoflavone } \\
(\mu \mathrm{M})\end{array}$ & $\begin{array}{c}\text { Dose of } \\
\text { cisplatin } \\
(\mu \mathrm{g} / \mathrm{ml})\end{array}$ & Effect & $\begin{array}{c}\text { CI } \\
\text { value }\end{array}$ & Efficacy \\
\hline 100 & 1 & 0.48 & 0.83 & Synergism \\
100 & 2 & 0.64 & 0.80 & Synergism \\
100 & 3 & 0.67 & 0.91 & Synergism \\
100 & 4 & 0.82 & 0.66 & Synergism \\
100 & 5 & 0.89 & 0.52 & Synergism \\
\hline
\end{tabular}

with cisplatin, we further aimed to identify which apoptotic pathway was activated by the combination treatment. A loss of the mitochondrial membrane potential $(\Delta \Psi \mathrm{m})$ was induced by the combination treatment (Figure $3 \mathrm{~A}$ and $\mathrm{B}$ ). Furthermore, treatment with the combination of amentoflavone and cisplatin resulted in the induction of BAK and BAX (Figure 3C) as well as the activation of cleaved caspase-9 (Figure 3D). Thus, the intrinsic caspase-dependent apoptotic pathway was activated by the combination treatment. However, as shown in the caspase- 8 analysis, the combination of amentoflavone with cisplatin may not effectively activate the extrinsic apoptotic signaling (Figure 3E). In addition, the activation of AIF and EndoG was confirmed by IF staining, which indicated also the activation of a caspase-independent apoptosis signaling (20, 21). As illustrated in Figure 3F and G, AIF and EndoG nuclear translocation was increased in the combination group as compared to the single treatment. In summary, amentoflavone may enhance cisplatin induced both intrinsic caspasedependent and independent apoptosis pathway in OSCC.

Amentoflavone enhances the cisplatin-induced suppression of invasion and migration of OSCC cells. To identify whether invasion and migration may be further reduced by amentoflavone combined with cisplatin, we performed invasion/migration transwell assay. As indicated in Figure 4A and $\mathrm{B}$, the percentage of cells that migrated was decreased in the combination group as compared to the single treatment groups. In addition, the number of invaded cells was also further reduced by the combined treatment as compared to the single treatment groups (Figure 4A and C).

\section{Discussion}

$\mathrm{NF}-\mathrm{kB}$, an oncogenic transcription factor, is known to promote cell growth, survival, angiogenesis, epithelial-mesenchymal transition, and invasion through upregulating the expression of $\mathrm{NF}-\mathrm{kB}$ target genes in cancers (22-25). Constitutive NF-kB activity is associated with chemoresistance and tumor metastasis 
A

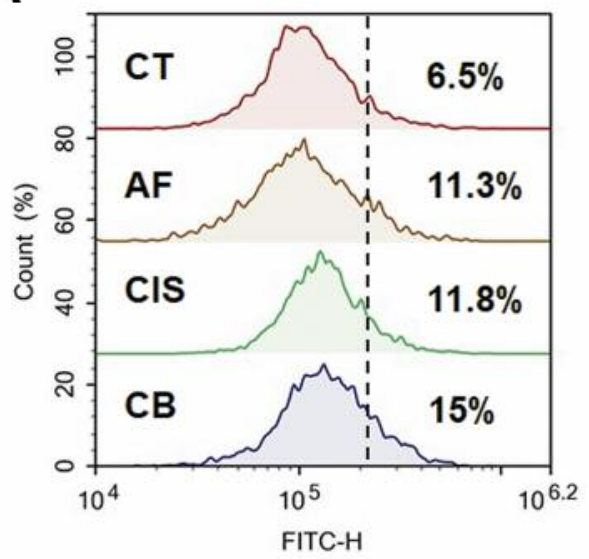

B

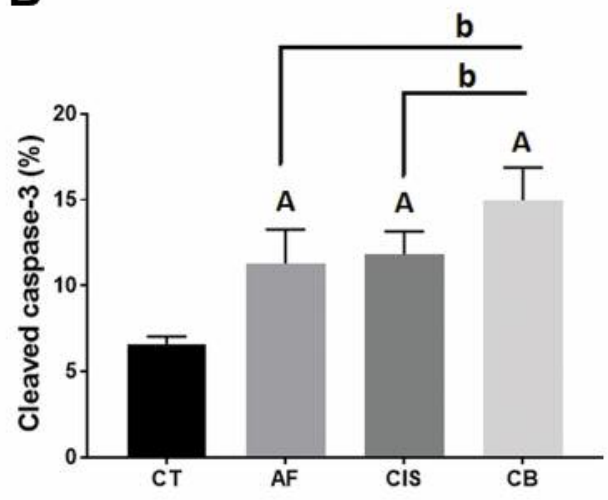

C
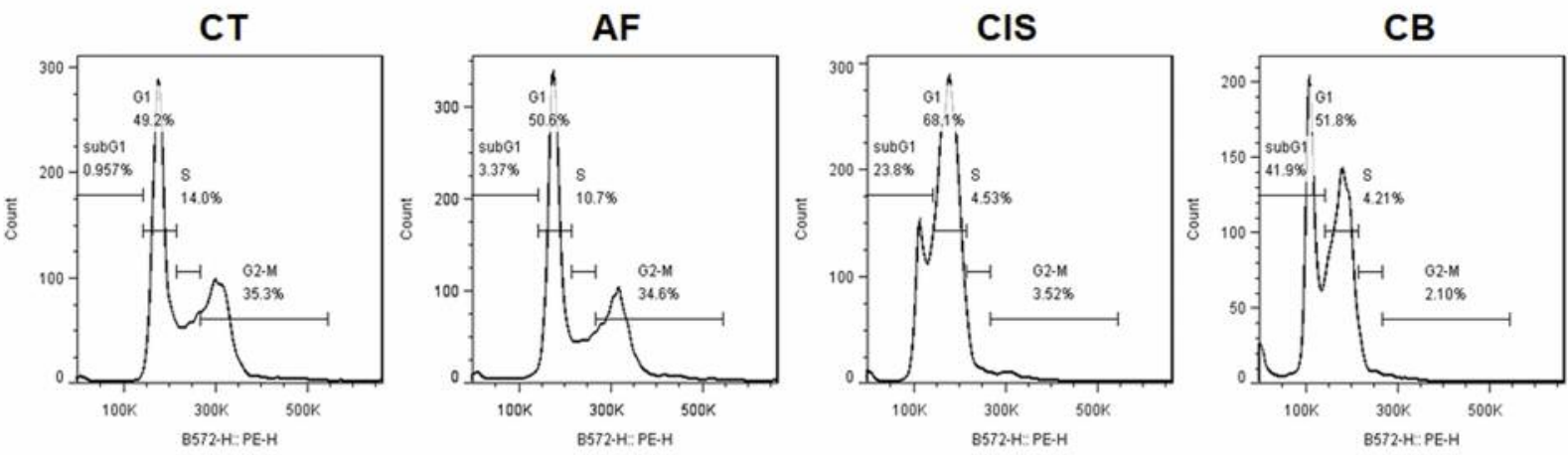

D

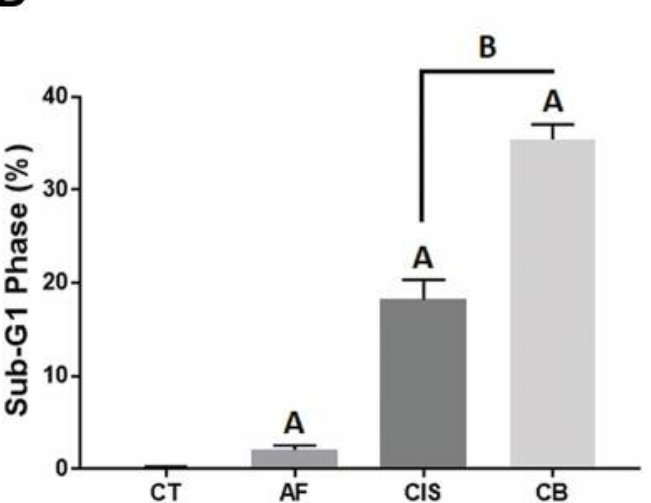

$\mathbf{E}$

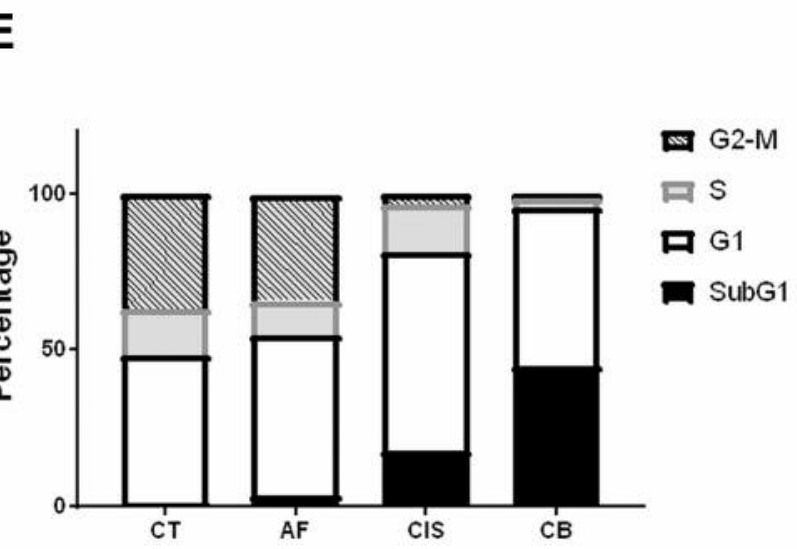

Figure 2. Apoptosis effect of amentoflavone and cisplatin in SAS cells. (A-B) The activation of cleaved-caspase-3 and (C-D) the accumulation of cells in the subG1 phase after treatment are displayed. (E) The quantification of cells in the different phases of the cell cycle after treatment. ${ }^{A} p-$ value $<0.01 \mathrm{vs}$. non-treated group; ${ }^{b} p$-value $<0.05,{ }^{B}$-value $<0.01 \mathrm{vs}$. single treatment group.

in OSCC patients $(26,27)$. Cisplatin triggers NF-kB activity, which in turn results in resistance of OSCC to cisplatin. Therefore, inhibition of NF-kB has been used to sensitize OSCC to cisplatin $(15,28)$. Our results showed that QNZ (a specific NF-KB inhibitor) and amentoflavone increase cisplatin- induced cytotoxicity and reduce cisplatin-triggered $\mathrm{NF}-\mathrm{kB}$ activity, respectively (Figure $1 \mathrm{~B}$ and $\mathrm{F}$ ). In addition, amentoflavone significantly enhanced cisplatin-mediated inhibition of cell proliferation, migration, and invasion of SAS cells (Figures 1C and 4). 
A
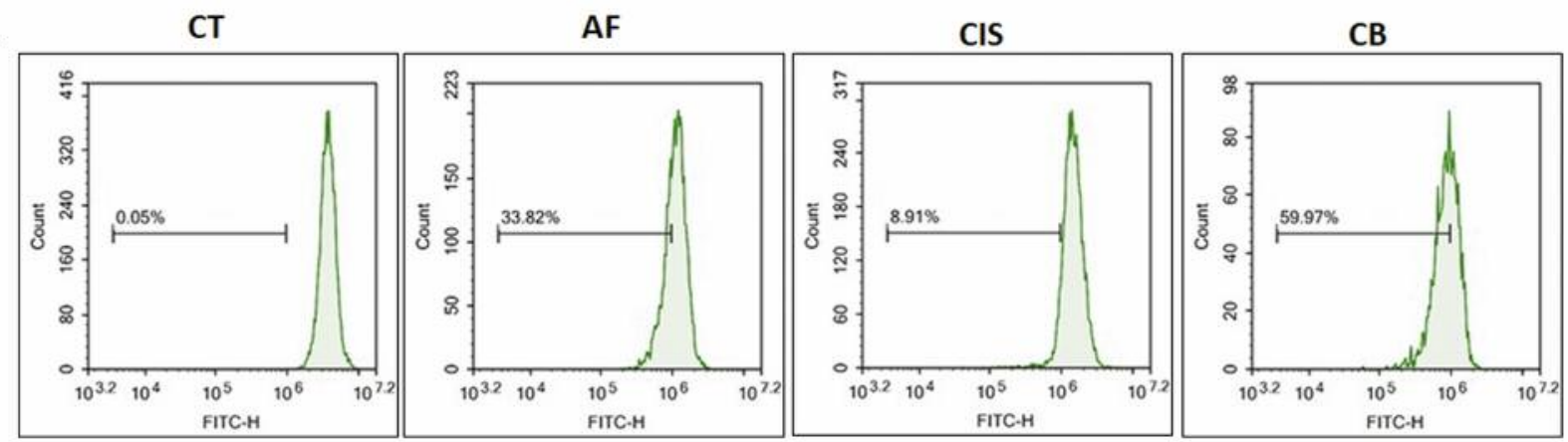

B

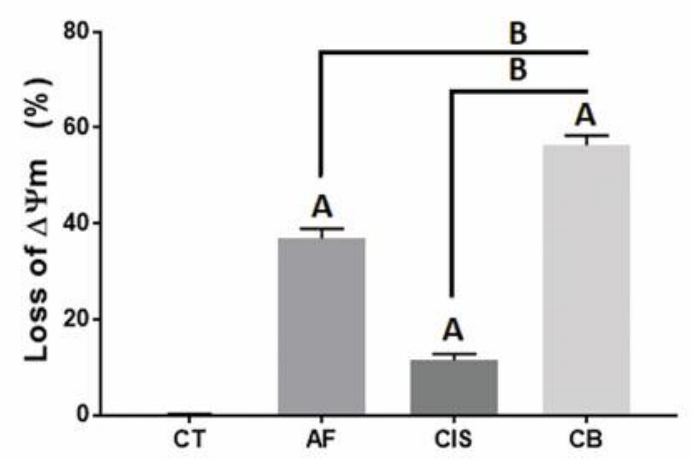

C

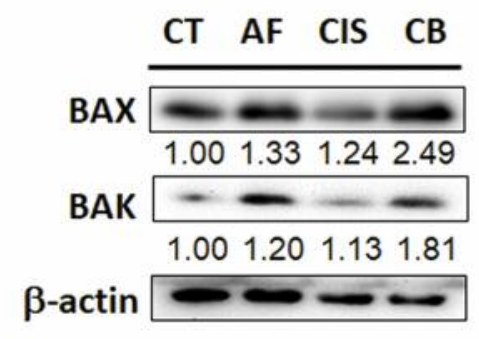

D
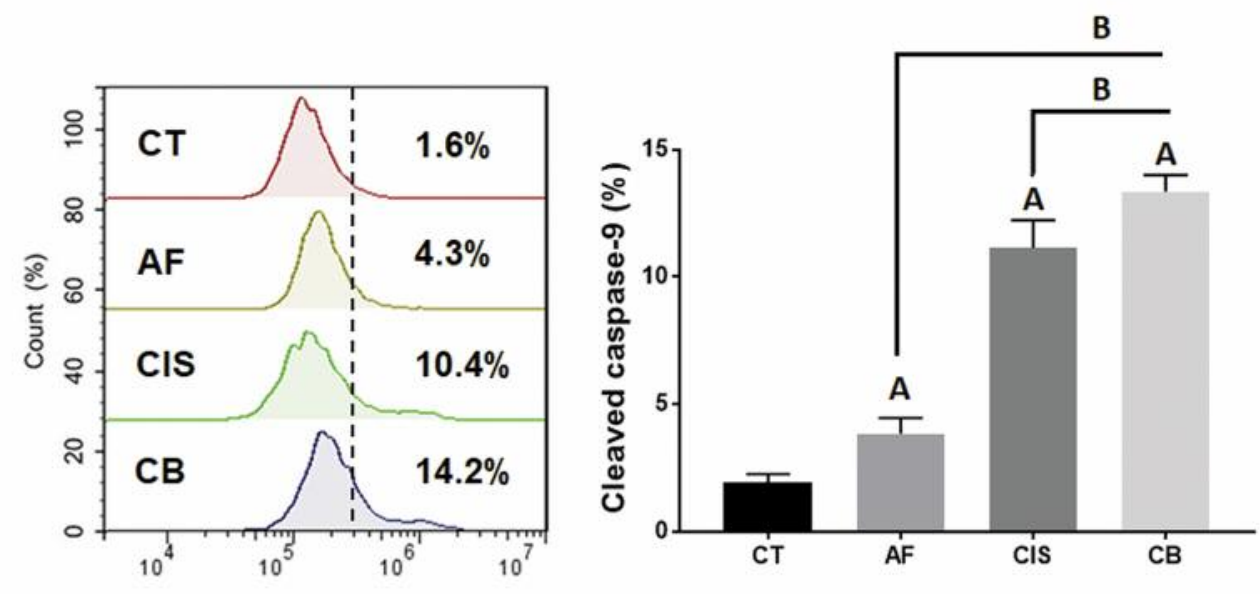

B530-H.: FITC-H

E
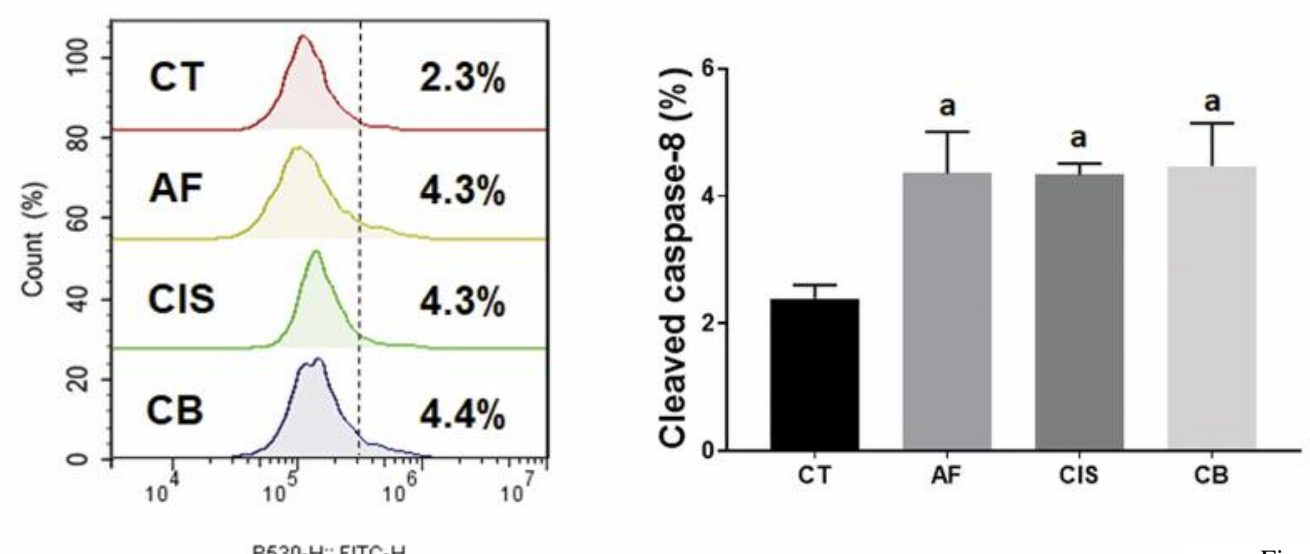

Figure 3. Continued 


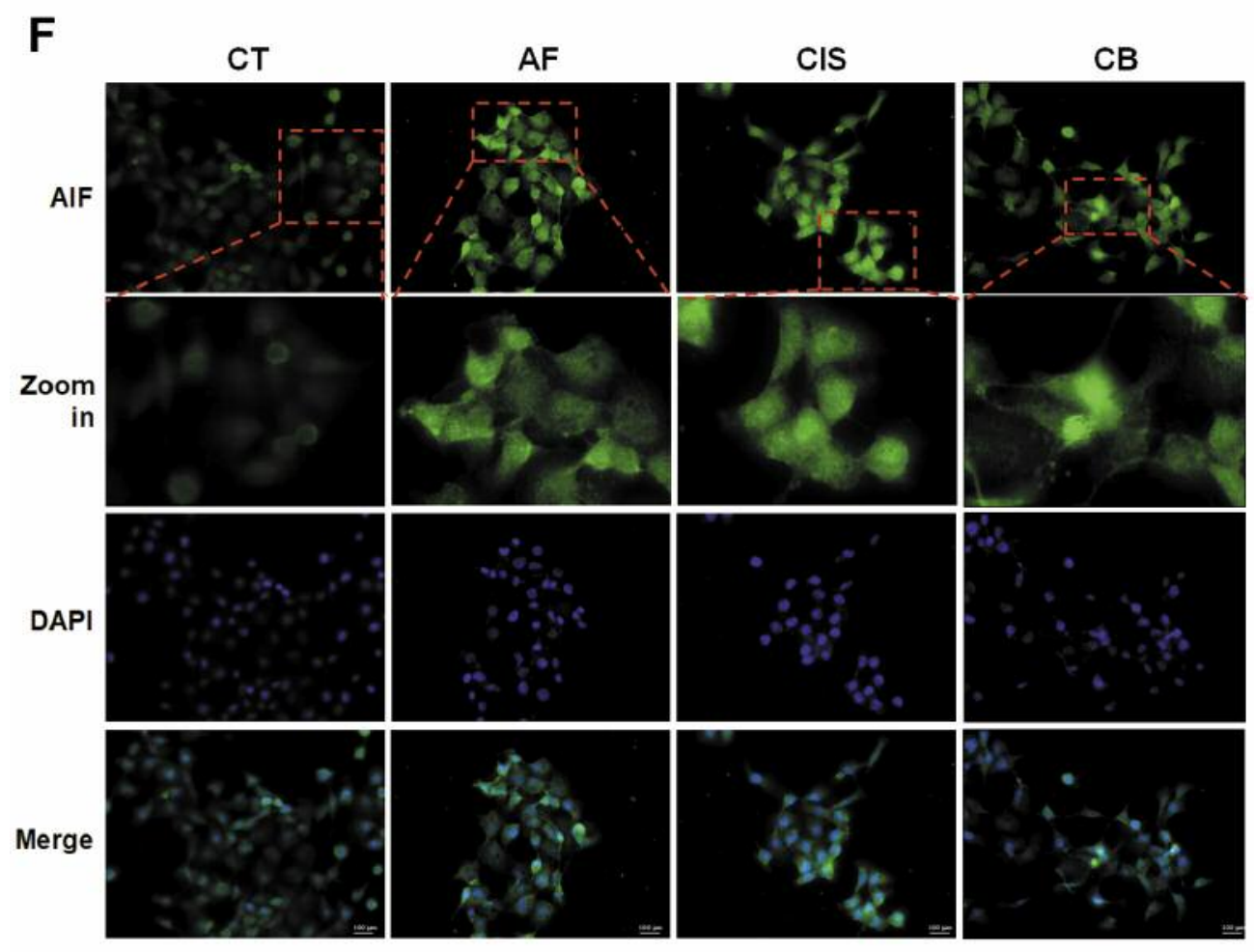

G

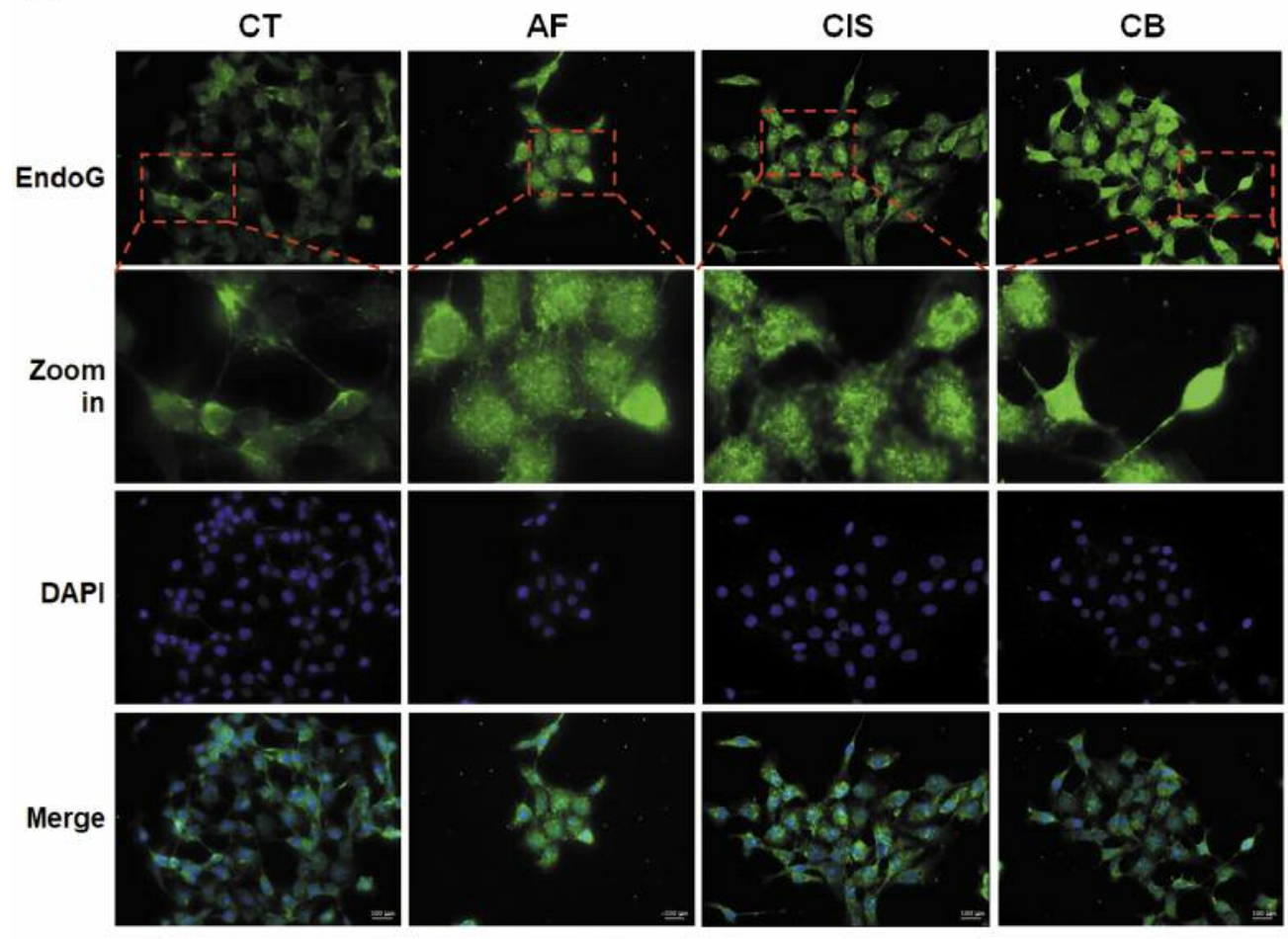

Figure 3. Intrinsic caspase-dependent and caspase-independent apoptosis were induced by amentoflavone combined with cisplatin in SAS cells. (A$B)$ The loss of $\Delta \Psi m$ after single and combined treatment is displayed. (C) The protein expression of BAX and BAK after single and combined treatment is displayed. The activation of $(D)$ cleaved caspase-9 and $(E)$ cleaved caspase-8 after single and combined treatment are displayed. The IF staining results of $(F)$ AIF and $(G)$ EndoG after single and combined treatment are displayed. ${ }^{a} p$-value $<0.05,{ }^{A} p$-value $<0.01$ vs. non-treated group; ${ }^{B}$ p-value $<0.01$ vs. single treatment group. 

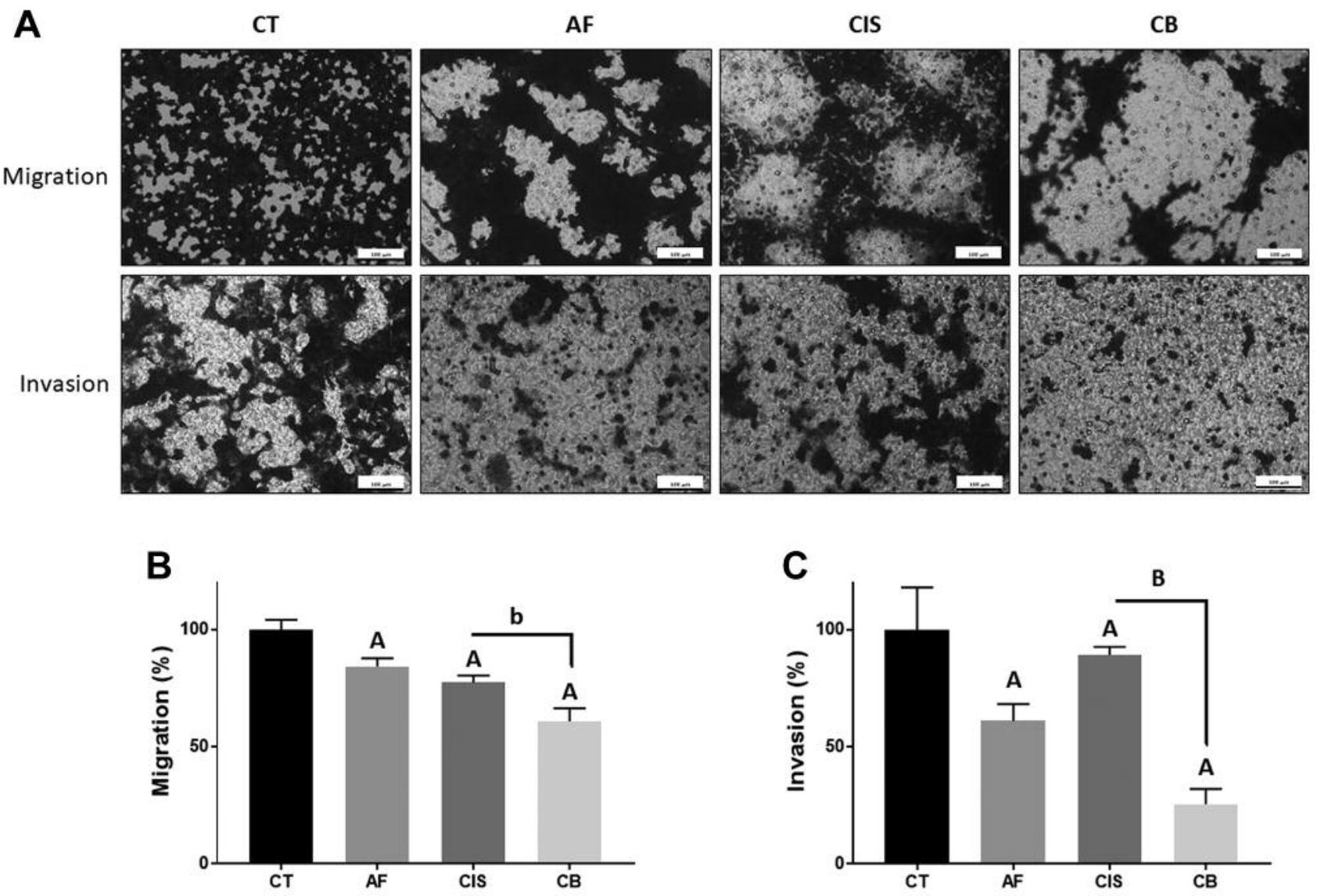

Figure 4. Migration and invasion effect were inhibited by amentoflavone combined with cisplatin in SAS cells. (A) The invasion and migration pattern on the transwell membrane are displayed. $(B-C)$ The invasion and migration percentage of cells in each group are quantified and displayed. ${ }^{A}$ p-value $<0.01 \mathrm{vs}$. non-treated group; ${ }^{b}$-value $<0.05,{ }^{B}$-value $<0.01 \mathrm{vs}$. single treatment group; scale bar $=100 \mu \mathrm{m}$.

Inhibition of tumor growth can be induced by anticancer agents through caspase-dependent and independent apoptotic pathways (29-31). During the initiation of the extrinsic and intrinsic apoptotic pathways, cleaved-caspase-8 and 9 participate in the regulation of DNA fragmentation via cleavage of caspase-3 $(32,33)$. Intrinsically, the proapoptotic proteins $\mathrm{BAX}$ and $\mathrm{BAK}$, initiate loss of the mitochondrial membrane potential $(\Delta \Psi \mathrm{m})$ and result in the release of cytochrome-c, apoptosis-inducing factor (AIF) and endonuclease G (EndoG) from mitochondria. Both AIF and endoG are caspaseindependent death effectors that translocate to the nucleus and induce apoptotic DNA fragmentation (34-36).

In this study, amentoflavone augmented the cisplatininduced apoptotic signaling. The combination of amentoflavone and cisplatin significantly increased expression of cleaved caspase-3 and induced cell accumulation in the sub- $\mathrm{G}_{1}$ phase, compared to amentoflavone or cisplatin single treatment (Figure 2). Different from the extrinsic and intrinsic apoptotic signaling triggered by the combination of amentoflavone and sorafenib in HCC (13), our results indicate that amentoflavone significantly enhanced cisplatin-induced loss of $\Delta \Psi \mathrm{m}$ and caspase- 9 cleavage, but not caspase- 8 cleavage in SAS cells (Figure 3A, B, D and E). In addition, the combination of amentoflavone and cisplatin further upregulated BAX and BAK expression compared to that induced by amentoflavone or cisplatin alone. The intrinsic apoptotic pathway, which is characterized by increased expression of BAX or BAK, was found to correlate with a favorable prognosis of OSCC patients (37). Notably, amentoflavone also intensified cisplatin-triggered AIF and EndoG nuclear translocation (Figure 3F and G).

In conclusion, the anti-OSCC effects elicited by cotreatment of amentoflavone with cisplatin are at least partly caused by NF-kB inactivation as well as by the induction of apoptosis through intrinsic caspase-dependent and independent pathways. With regard to the antitumor efficacy and sensitization effect of amentoflavone, we suggest that amentoflavone may cause therapeutic benefits to OSCC patients treated with cisplatin. 


\section{Conflicts of Interest}

The Authors declare that they have no conflicts of interest in relation to this article.

\section{Authors' Contributions}

Data curation, CH Chen, YC Huang, ZL Tan, and FT Hsu; funding acquisition, $\mathrm{CH}$ Chen and FT Hsu; writing - original draft, HF Tu, CJ Tsai, YC Chuang, YJ Lee and FT Hsu; writing - review, HF Tu, TC Liu and FT Hsu. All Authors have read and agreed to the published version of the manuscript.

\section{Acknowledgements}

Experiments and data analysis were performed in part through the use of the Medical Research Core Facilities Center, Office of Research \& Development at China Medical University, Taichung, Taiwan.

\section{Funding}

This study was supported by China Medical University, Taichung, Taiwan (grant number: CMU109-MF-07), Show Chwan Memorial Hospital, Changhua, Taiwan (Grant number: SRD-109002), National Yang-Ming University Hospital, Yilan, Taiwan (Grant number: RD2019-002), Ministry of Science and Technology, Taipei, Taiwan (Grant number: MOST 108-2314-B-010-014), respectively. This work was also financially supported by the "Drug Development Center, China Medical University" from The Featured Areas Research Center Program within the framework of the Higher Education Sprout Project by the Ministry of Education (MOE) in Taiwan.

\section{References}

1 Bugshan A and Farooq I: Oral squamous cell carcinoma: Metastasis, potentially associated malignant disorders, etiology and recent advancements in diagnosis. F1000Research 9: 229-229, 2020. PMID: 32399208. DOI: 10.12688/f1000research.22941.1

2 Lin CW, Chin HK, Lee SL, Chiu CF, Chung JG, Lin ZY, Wu CY, Liu YC, Hsiao YT, Feng CH, Bai LY and Weng JR: Ursolic acid induces apoptosis and autophagy in oral cancer cells. Environ Toxicol 34(9): 983-991, 2019. PMID: 31062913. DOI: 10.1002/tox.22769

3 Li M, Li Z, Li J, Jin L, Jin C, Han C, Ji X and Sun F: Enhanced antitumor effect of cisplatin in human oral squamous cell carcinoma cells by tumor suppressor grim-19. Mol Med Rep 12(6): 8185-8192, 2015. PMID: 26458285. DOI: 10.3892/mmr.2015.4423

4 Kangboonruang $K$, Wongtrakoongate $P$, Lertsuwan K, Khachonkham S, Changkaew P, Tangboonduangjit P, Siripoon $\mathrm{T}$, Ngamphaiboon $\mathrm{N}$ and Chairoungdua A: Malat1 decreases the sensitivity of head and neck squamous cell carcinoma cells to radiation and cisplatin. Anticancer Res 40(5): 2645-2655, 2020. PMID: 32366409. DOI: 10.21873/anticanres.14235

5 Huang Z, Zhang Y, Li H, Zhou Y, Zhang Q, Chen R, Jin T, Hu $\mathrm{K}$, Li S, Wang Y, Chen W and Huang Z: Vitamin d promotes the cisplatin sensitivity of oral squamous cell carcinoma by inhibiting $1 \mathrm{cn} 2$-modulated nf-kb pathway activation through rps3. Cell Death Dis 10(12): 936, 2019. PMID: 31819048. DOI: 10.1038/s41419-019-2177-x

6 Khoo XH, Paterson IC, Goh BH and Lee WL: Cisplatinresistance in oral squamous cell carcinoma: Regulation by tumor cell-derived extracellular vesicles. Cancers (Basel) 11(8), 2019. PMID: 31416147. DOI: 10.3390/cancers11081166

7 Fan KH, Chen YC, Lin CY, Kang CJ, Lee LY, Huang SF, Liao $\mathrm{CT}, \mathrm{Ng} \mathrm{SH}$, Wang $\mathrm{HM}$ and Chang JT: Postoperative radiotherapy with or without concurrent chemotherapy for oral squamous cell carcinoma in patients with three or more minor risk factors: A propensity score matching analysis. Radiat Oncol 12(1): 184, 2017. PMID: 29166942. DOI: 10.1186/s13014-0170910-0

8 Shen J, Huang C, Jiang L, Gao F, Wang Z, Zhang Y, Bai J, Zhou $\mathrm{H}$ and Chen Q: Enhancement of cisplatin induced apoptosis by suberoylanilide hydroxamic acid in human oral squamous cell carcinoma cell lines. Biochem Pharmacol 73(12): 1901-1909, 2007. PMID: 17445779. DOI: 10.1016/j.bcp.2007.03.009

9 Yu S, Yan H, Zhang L, Shan M, Chen P, Ding A and Li SFY: A review on the phytochemistry, pharmacology, and pharmacokinetics of amentoflavone, a naturally-occurring biflavonoid. Molecules (Basel, Switzerland) 22(2): 299, 2017. PMID: 28212342. DOI: 10.3390/molecules22020299

10 Chen JH, Chen WL and Liu YC: Amentoflavone induces antiangiogenic and anti-metastatic effects through suppression of $\mathrm{nf}-$ $\mathrm{Kb}$ activation in mcf-7 cells. Anticancer Res 35(12): 6685-6693, 2015. PMID: 26637885.

11 Lee KC, Tsai JJ, Tseng CW, Kuo YC, Chuang YC, Lin SS and Hsu FT: Amentoflavone inhibits erk-modulated tumor progression in hepatocellular carcinoma in vitro. In Vivo 32(3): 549-554, 2018. PMID: 29695559. DOI: 10.21873/invivo.112274

12 Hsu FT, Chiang IT, Kuo YC, Hsia TC, Lin CC, Liu YC and Chung JG: Amentoflavone effectively blocked the tumor progression of glioblastoma via suppression of ERK/NF-kB signaling pathway. Am J Chin Med 47(4): 913-931, 2019. PMID: 31096773. DOI: 10.1142/S0192415X1950048

13 Chen WL, Hsieh CL, Chen JH, Huang CS, Chen WT, Kuo YC, Chen CY and Hsu FT: Amentoflavone enhances sorafenibinduced apoptosis through extrinsic and intrinsic pathways in sorafenib-resistant hepatocellular carcinoma sk-hep1 cells in vitro. Oncol Lett 14(3): 3229-3234, 2017. PMID: 28927070. DOI: $10.3892 / \mathrm{ol} .2017 .654$

14 Chen JH, Chiang IT and Hsu FT: Protein kinase b inactivation is associated with magnolol-enhanced therapeutic efficacy of sorafenib in hepatocellular carcinoma in vitro and in vivo. Cancers (Basel) 12(1), 2019. PMID: 31905887 . DOI: 10.3390/cancers 12010087

15 Chou TC: Drug combination studies and their synergy quantification using the chou-talalay method. Cancer Res 70(2): 440-446, 2010. PMID: 20068163. DOI: 10.1158/00085472.CAN-09-1947

16 Hsu FT, Chiang IT and Wang WS: Induction of apoptosis through extrinsic/intrinsic pathways and suppression of erk/nf$\mathrm{kb}$ signalling participate in anti-glioblastoma of imipramine. $\mathrm{J}$ Cell Mol Med 24(7): 3982-4000, 2020. PMID: 32149465. DOI: $10.1111 / \mathrm{jcmm} .15022$

17 Chen WT, Hsu FT, Liu YC, Chen CH, Hsu LC and Lin SS: Fluoxetine induces apoptosis through extrinsic/intrinsic pathways and inhibits erk/nf-kb-modulated anti-apoptotic and invasive potential in hepatocellular carcinoma cells in vitro. Int J Mol Sci 20(3), 2019. PMID: 30754643. DOI: 10.3390/ijms20030757 
18 Su CM, Weng YS, Kuan LY, Chen JH and Hsu FT: Suppression of $\mathrm{pkc \delta} / \mathrm{nf}-\mathrm{kb}$ signaling and apoptosis induction through extrinsic/intrinsic pathways are associated magnolol-inhibited tumor progression in colorectal cancer in vitro and in vivo. Int $\mathbf{J}$ Mol Sci 21(10): 3527, 2020. PMID: 32429376. DOI: $10.3390 / \mathrm{ijms} 21103527$

19 Pan PJ, Liu YC and Hsu FT: Protein kinase b and extracellular signal-regulated kinase inactivation is associated with regorafenib-induced inhibition of osteosarcoma progression in vitro and in vivo. J Clin Med 8(6), 2019. PMID: 31528215. DOI: 10.7150/jca.31045

$20 \mathrm{Li} \mathrm{LY}$, Luo X and Wang X: Endonuclease $\mathrm{g}$ is an apoptotic dnase when released from mitochondria. Nature 412(6842): 95-99, 2001. PMID: 11452314. DOI: 10.1038/35083620

21 Candé C, Vahsen N, Garrido C and Kroemer G: Apoptosisinducing factor (aif): Caspase-independent after all. Cell Death Differ 11(6): 591-595, 2004. PMID: 15017385. DOI: 10.1038/ sj.cdd. 4401400 .

22 Park $\mathrm{MH}$ and Hong JT: Roles of $\mathrm{nf}-\mathrm{kb}$ in cancer and inflammatory diseases and their therapeutic approaches. Cells 5(2), 2016. PMID: 27043634. DOI: 10.3390/cells5020015

23 Pires BR, Mencalha AL, Ferreira GM, de Souza WF, MorgadoDíaz JA, Maia AM, Corrêa S and Abdelhay ES: Nf-kappab is involved in the regulation of emt genes in breast cancer cells. PLoS One 12(1): e0169622, 2017. PMID: 28107418. DOI: 10.1371/journal.pone.0169622

24 Kuo YC, Lin WC, Chiang IT, Chang YF, Chen CW, Su SH, Chen CL and Hwang JJ: Sorafenib sensitizes human colorectal carcinoma to radiation via suppression of $\mathrm{nf}-\mathrm{kb}$ expression in vitro and in vivo. Biomed Pharmacother 66(1): 12-20, 2012. PMID: 22265104. DOI: 10.1016/j.biopha.2011.09.011

25 Nariai Y, Mishima K, Yoshimura Y and Sekine J: Fap-1 and nf$\mathrm{Kb}$ expressions in oral squamous cell carcinoma as potential markers for chemo-radio sensitivity and prognosis. Int J Oral Maxillofac Surg 40(4): 419-426, 2011. PMID: 21176871. DOI: 10.1016/j.ijom.2010.10.020

26 Yan M, Xu Q, Zhang P, Zhou X-J, Zhang Z-Y and Chen W-T: Correlation of NF-kB signal pathway with tumor metastasis of human head and neck squamous cell carcinoma. BMC Cancer 10(1): 437, 2010. PMID: 20716363. DOI: 10.1186/1471-2407$10-437$

27 Almeida LO, Abrahao AC, Rosselli-Murai LK, Giudice FS, Zagni C, Leopoldino AM, Squarize $\mathrm{CH}$ and Castilho RM: NFKB mediates cisplatin resistance through histone modifications in head and neck squamous cell carcinoma (hnscc). FEBS Open Bio 4: 96-104, 2013. PMID: 24490130. DOI: 10.1016/j.fob.2013.12.003

28 Li X, Guo S, Xiong X-K, Peng B-Y, Huang J-M, Chen M-F, Wang F-Y and Wang J-N: Combination of quercetin and cisplatin enhances apoptosis in oscc cells by downregulating xiap through the NF-kB pathway. J Cancer 10(19): 4509-4521, 2019. PMID: 31528215. DOI: $10.7150 /$ jca.31045
29 Ramadevi Mani S and Lakshmi BS: G1 arrest and caspasemediated apoptosis in hl-60 cells by dichloromethane extract of centrosema pubescens. Am J Chin Med 38(6): 1143-1159, 2010. PMID: 21061467. DOI: 10.1142/S0192415X10008536

30 Xue M, Ji X, Xue C, Liang H, Ge Y, He X, Zhang L, Bian K and Zhang L: Caspase-dependent and caspase-independent induction of apoptosis in breast cancer by fucoidan via the $\mathrm{pi} 3 \mathrm{k} / \mathrm{akt} / \mathrm{gsk} 3 \beta$ pathway in vivo and in vitro. Biomed Pharmacother 94: 898-908, 2017. PMID: 28810530. DOI: 10.1016/j.biopha.2017.08.013

31 Jan R and Chaudhry GE: Understanding apoptosis and apoptotic pathways targeted cancer therapeutics. Adv Pharm Bull 9(2): 205-218, 2019. PMID: 31380246. DOI: 10.15171/apb.2019.024

32 Raducka-Jaszul O, Bogusławska DM, Jędruchniewicz N and Sikorski AF: Role of extrinsic apoptotic signaling pathway during definitive erythropoiesis in normal patients and in patients with $\beta$-thalassemia. Int J Mol Sci 21(9): 3325, 2020. PMID: 32397135. DOI: 10.3390/ijms21093325

33 Kitazumi I and Tsukahara M: Regulation of DNA fragmentation: The role of caspases and phosphorylation. FEBS J 278(3): 427-441, 2011. PMID: 21182594. DOI: 10.1111/j.1742-4658.2010.07975.x

34 Nechushtan A, Smith CL, Lamensdorf I, Yoon SH and Youle RJ: Bax and bak coalesce into novel mitochondria-associated clusters during apoptosis. J Cell Biol 153(6): 1265-1276, 2001. PMID: 11402069 . DOI: $10.1083 /$ jcb.153.6.1265

35 Cregan SP, Dawson VL and Slack RS: Role of aif in caspasedependent and caspase-independent cell death. Oncogene 23(16): 2785-2796, 2004. PMID: 15077142. DOI: 10.1038/sj.onc.1207517

36 Dyshlovoy SA, Pelageev DN, Hauschild J, Borisova KL, Kaune M, Krisp C, Venz S, Sabutskii YE, Khmelevskaya EA, Busenbender T, Denisenko VA, Pokhilo ND, Atopkina LN, Graefen M, Schlüter H, Stonik VA, Bokemeyer C, Anufriev VP and von Amsberg G: Successful targeting of the warburg effect in prostate cancer by glucose-conjugated 1,4-naphthoquinones. Cancers (Basel) 11(11), 2019. PMID: 31671612 . DOI: $10.3390 /$ cancers 11111690

37 Sasahira $\mathrm{T}$ and Kirita T: Hallmarks of cancer-related newly prognostic factors of oral squamous cell carcinoma. Int $\mathrm{J}$ Mol Sci 19(8), 2018. PMID: 30115834. DOI: 10.3390/ijms 19082413
Received October 9, 2020

Revised October 19, 2020

Accepted October 20, 2020 